\title{
Ekstraksi dan Identifikasi Komponen Utama Pasir Putih dari Desa Marinsow Kabupaten Minahasa Utara dengan Pengujian XRF dan XRD
}

\author{
Billy G. Langi* ,Meitij J. Rampe, Soenandar M. T. Tengker
}

Kimia FMIPA,Universitas Negeri Manado,Tondano,95619,Indonesia

INFO ARTIKEL

\begin{tabular}{l}
\hline Diterima 6 Agustus 2020 \\
Disetujui 26 Oktober 2020 \\
\hline Key word: \\
White sand \\
Main component \\
Extraction \\
$\mathrm{SiO}_{2}$ \\
$\mathrm{XRD}$ \\
$\mathrm{XRF}$ \\
\\
\hline Kata kunci: \\
$\mathrm{Pasir}$ Putih \\
$\mathrm{Komponen} \mathrm{Utama}$ \\
Ekstraksi \\
$\mathrm{SiO} 2$ \\
$\mathrm{XRD}$ \\
$\mathrm{XRF}$ \\
\end{tabular}

${ }^{*} e$-mail:

billygabriellangi2425@gmail.co $m$

\begin{abstract}
A B STRACT
North Sulawesi has material in the form of white sand which can be maximized in many areas because white sand has a constituent composition, namely $\mathrm{SiO} 2, \mathrm{CaO}$, $\mathrm{Fe} 2 \mathrm{O} 3, \mathrm{TiO} 2, \mathrm{MgO}$. This study aims to identify the main component composition of white sand through XRF testing and the results of white sand extraction from the Marinsow village using XRD testing to determine the characteristics of crystals. The extraction and testing process using XRF and XRD has been carried out on white sand samples taken in the village of Marinsow. The results of identification of white sand constituent components through XRF testing, namely $\mathrm{CaO}$ is the largest major component of white sand in the village of Marinsow, which is $89.97 \%$. The content of $\mathrm{SiO} 2$ compounds in white sand (Marinsow) is $1.41 \%$. Other components found in white sand from Marinsow village, Minahasa Utara district include $\mathrm{MgO}$ as much as $5.85 \%$, SrO as much as $2.31 \%$, Fe2O3 as much as $0.277 \%$, TiO2 was $0.079 \%$, $\mathrm{Cr} 2 \mathrm{O} 3$ was $0.032 \%$, Nb2O5 was $0.0238 \%$, MoO3 was $0.0159 \%$, SnO2 was $0.0082 \%$, Sb2O3 was $0.0079 \%$ and $\mathrm{RuO} 4$ was $0.0074 \%$. XRD test results on white sand taken in the village of Marinsow show that white sand has a calcite crystal structure $(\mathrm{CaO})$ and for the SiO2 silica component is quartz.
\end{abstract}

\section{A B STRAK}

Sulawesi utara memiliki material dalam bentuk pasir putih yang dapat di maksimalkan dalam banyak bidang karena Pasir putih mempunyai komposisi penyusun yaitu $\mathrm{SiO}_{2}, \mathrm{CaO}_{2} \mathrm{Fe}_{2} \mathrm{O}_{3}, \mathrm{TiO}_{2}, \mathrm{MgO}$. Penelitian ini bertujuan mengidentifikasi komposisi komponen utama pasir putih Melalui pengujian XRF dan hasil ekstraksi pasir putih dari desa marinsow menggunakan Pengujian XRD untuk mengetahui kararteristik Kristal. Sudah di lakukan proses Ekstraksi dan pengujian menggunakan XRF dan XRD terhadap sampel pasir putih yang di ambil di desa marinsow. Hasil identifikasi komponen penyusun pasir putih melalui pengujian XRF yakni $\mathrm{CaO}$ merupakan Komponen utama yang paling besar penyusun pasir putih di desa marinsow yakni sebanyak $89,97 \%$. kandungan senyawa $\mathrm{SiO}_{2}$ pada pasir putih (Marinsow) adalah sebanyak 1,41 \% Komponen-komponen lain yang yang terdapat pada pasir putih dari desa marinsow kabupaten minahasa utara antara lain $\mathrm{MgO}$ sebanyak 5,85\%,SrO sebanyak 2,31 \%, $\mathrm{Fe}_{2} \mathrm{O}_{3}$ sebanyak 0,277\%, $\mathrm{TiO}_{2}$ sebanyak $0,079 \%, \mathrm{Cr}_{2} \mathrm{O}_{3}$ yakni $0,032 \%, \mathrm{Nb}_{2} \mathrm{O}_{5}$ yakni $0,0238 \%, \mathrm{MoO}_{3}$ sebanyak 0,0159\%, $\mathrm{SnO}_{2}$ sebanyak 0,0082 \%, $\mathrm{Sb}_{2} \mathrm{O}_{3}$ 0,0079 \% dan $\mathrm{RuO}_{4}$ sebanyak $0,0074 \%$. Hasil pengujian XRD pada pasir putih yang di ambil di desa marinsow memberikan hasil bahwa pasir putih mempunyai struktur Kristal kalsit $(\mathrm{CaO})$ dan untuk komponen silika $\mathrm{SiO}_{2}$ berupa quartz.

\section{Pendahuluan}

Sulawesi utara merupakan salah satu daerah yang memiliki kekayaan sumber daya alam dalam bentuk material yang cukup melimpah di Indonesia, salah satu potensi material yang dapat dimanfaatkan adalah pasir 
Putih. Pasir Putih dapat ditemukan di beberapa daerah Sulawesi Utara contohnya seperti di desa Marinsow Kecamatan Likupang Timur Kabupaten Minahasa utara (Gambar 1). Pasir kuarsa sering juga disebut pasir Putih mengandung mineral yang terjadi akibat pelapukan,dimana Bahan pengisi pasir kuarsa merupakan bahan galian yang mengandung Kristal silika $\left(\mathrm{SiO}_{2}\right)$ [1].

Senyawa-senyawa seperti $\mathrm{SiO}_{2}, \mathrm{CaO}_{2} \mathrm{Fe}_{2} \mathrm{O}_{3}$, $\mathrm{TiO}_{2}, \mathrm{CaO}, \mathrm{MgO}$, merupakan senyawa-senyawa yang terkandung dalam pasir kuarsa dan sebagai penyusun komponen utama pasir kuarsa yang memiliki ciri-ciri fisik atau warna yang berbeda sesuai dengan komponen penyusun dan pengotor yang ada [2]. Untuk Mengidentifikasi komposisi komponen utama pada pasir putih dari desa marinsow menggunakan pengujian XRF dan hasil ekstraksi menggunakan metode alkali fusion dengan Pengujian XRD pada pasir putih yang berasal di desa Marinsow Kabupaten Minahasa Utara untuk mengetahui karakteristik dari Kristal silika $\left(\mathrm{SiO}_{2}\right)$.

Silika yang di kenal pada umumnya yaitu $\mathrm{SiO}_{2}$ dimana satu atom $\mathrm{Si}$ (silika)di gabungkan dengan dua atom $\mathrm{O}_{2}$ (dioksida) pada umumnya silika yang ada di alam ada beberapa bentuk yakni, silika dalam bentuk Kristalin dan silika dalam bentuk Non-Kristalin atau sering di sebut amorf $[3,4]$. Silika yang paling sering dan paling banyak di Temukan yaitu silika bentuk Kristalin dimana jenis silika jenis ini sering di temukan dalam batu-batuan pasir,Granit,dan Kristobalit [5].

Silika merupakan salah satu dari modifikasi kristal yang paling dikenal sebagai kuarsa [6]. Kuarsa, tridimit dan kristobalit merupakan Bentuk-bentuk polimorf dari silica yang dapat di bedakan melalui kestabilan terhadap perubahan suhu panas yaitu: Kuarsa, sampai pada suhu $870{ }^{\circ} \mathrm{C}$,Tridimit, pada suhu 870-1470 ${ }^{\circ} \mathrm{C}$,Kristobalit, pada suhu $1470{ }^{\circ} \mathrm{C}$ sampai titik leburnya $17300^{\circ} \mathrm{C}$ [7].

$\mathrm{SiO}_{2}$ (silika) merupakan bahan Mineral Penyusun Pasir Kuarsa/pasir Putih dimana silika yang terkandung dalam pasir Putih/kuarsa dapat di ekstraksi dan di identifikasi mengunakan metode flouresensi sinar-X (XRF) [8,9]. XRF merupakan alat yang digunakan untuk menganalisis komposisi kimia beserta konsentrasi secara kualitatif maupun kuantitatif dimana Analisis kualitatif dilakukan untuk menganalisi jenis unsur yang terkandung dalam bahan dan analisis kuantitatif dilakukan untuk menentukan konsentrasi dari unsur-unsur yang terkandung dalam sample dengan menggunakan metode spektrometri dan dikarakterisasi dengan menggunakan metode XRD[10-13]. XRD merupakan sebuah Teknik analisis yang selalu digunakan dalam hal mengidentifikasi kemunculan fase kristal di dalam materialmaterial sampel dan dalam bentuk bubuk. Mengkarakterisasi sifat-sifat struktur pada sampel uji dimana pada XRD memiliki prinsip kerja yaitu sinar-X merefleksikan atau memantulkan sinar kepada bidang-bidang atom kristal dari material sampel yang di uji sehingga kita dapat mengkarakterisasi karakteristik pada sampel uji $[14,15]$.

Untuk itu Tujuan penelitian adalah mengidentifikasi komposisi komponen utama hasil ekstraksi menggunakan metode alkali fusion pada pasir putih yang berasal di desa Marinsow Kabupaten Minahasa Utara melalui pengujian XRF dan XRD.

\section{Bahan dan Metode}

Sampel pasir putih di ambil di Desa Marinsow kecamatan Likupang Timur Kabupaten Minahasa Utara.

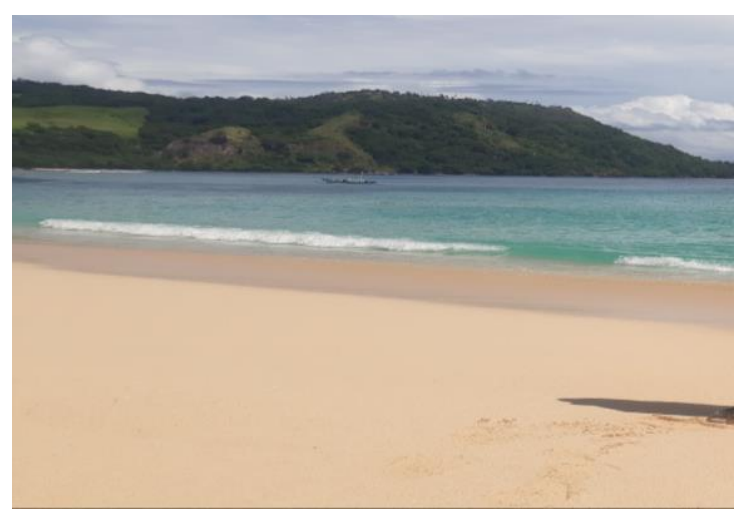

Gambar 1. Pantai di desa marinsow kecamatan Likupang timur Kabupaten Minahasa Utara

Pasir putih terlebih dahulu di cuci dengan aquades dan selanjutnya dibersikan/dipisahkan dari pengotor [16]. Pasir Putih di haluskan menggunakan lumpang dan alu, selanjutnya di ayak dengan ayakan 40 mesh. Serbuk pasir kuarsa hasil ayakan direndam dengan $\mathrm{HCl} 20 \%$ 
dalam Beaker glass selama 12 jam untuk melarutkan berbagai senyawa pengotor dalam pasir. Selanjutnya dilakukan pencucian pasir dengan menggunakan aquades sebanyak 3 sampai 4 kali atau sampai air cucian menjadi pH netral ( $\mathrm{pH} 6$ - 7). Serbuk Pasir kemudian dikeringkan dengan cara diangin-anginkan.

Proses ekstraksi di lakukan dengan menggunakan metode alkali fusion (gambar 2) yaitu menggunakan $\mathrm{NaOH}$ (basa) sebagai pelarut dan di stirrer selama 4 jam dan pemanasan sampai terbentuk gel-gel berwarna putih (persamaan 1) [17-19]. Larutan gel kemudian di titrasi menggunakan $\mathrm{HCl}$ (asam) (persamaan 2), Kemudian sampel hasil ekstraksi di lakukan pengujian karakterisasi Kristal menggunakan XRD dan untuk sampel sebelum ekstraksi di lakukan identifikasi Komponen pasir putih menggunakan XRF.

$\mathrm{SiO}_{2(\mathrm{~s})}+2 \mathrm{NaOH}_{(\mathrm{aq})} \longrightarrow \mathrm{Na}_{2} \mathrm{SiO}_{3}(\mathrm{aq})+\mathrm{H}_{2} \mathrm{O}_{(\mathrm{aq})}(1)$

$\mathrm{Na}_{2} \mathrm{SiO}_{3(\mathrm{aq})}+2 \mathrm{HCl}_{(\mathrm{aq})} \rightarrow \mathrm{SiO}_{2(\mathrm{~s})}+2 \mathrm{NaCl}_{(\mathrm{aq})}+\mathrm{H}_{2} \mathrm{O}_{(\mathrm{aq})}(2)$

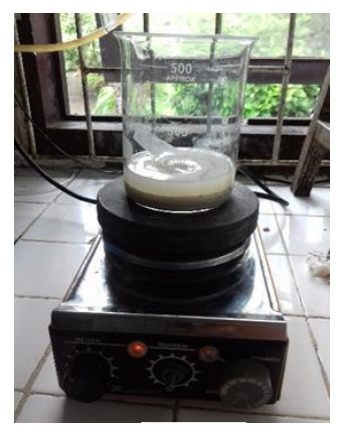

(a)

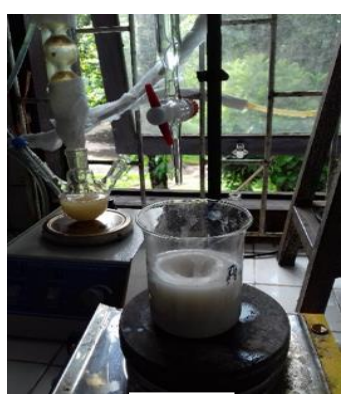

Gambar 2. Proses Alkali fusion dan F'roses

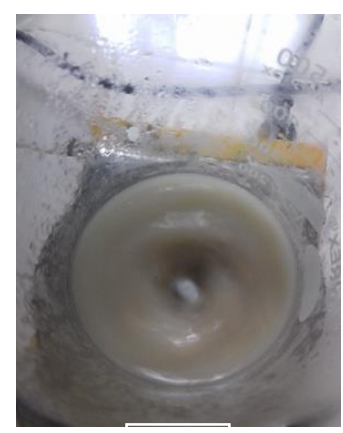

(b)

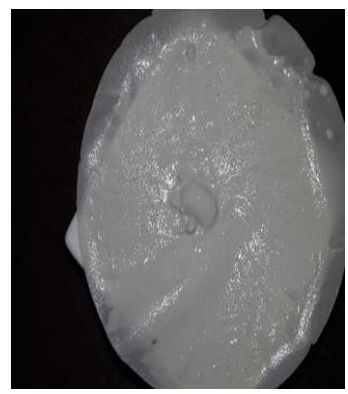

(d) pembentukan silika (a) Pemanasan dan Stirerr

(b) setelah 3 jam mulai terbentuk gel-gel berwarna putih (c) Titrasi Menggunakan $\mathrm{HCl}$. (d) Penyaringan Silika.

\section{Hasil dan Pembahasan}

Hasil Uji XRF

Hasil XRF dari sampel pasir putih di sajikan pada tabel 1 dimana terlihat bahwa kandungan unsur kimia dari pasir putih yang paling tinggi adalah $\mathrm{Ca}, \mathrm{Mg}$ dan $\mathrm{Sr}$ kemudian Si. Jika diolah menggunakan software yang tersedia pada alat XRF maka di peroleh kandungan senyawa $\mathrm{SiO}_{2}$ pada pasir putih (Marinsow) adalah sebanyak 1,41 \% (Gambar 3).

Tabel 1. Hasil XRF Sampel Pasir Putih (oksida)

\begin{tabular}{ccc}
\hline Senyawa & $\mathrm{m} / \mathrm{m} \%$ & StdErr \\
\hline $\mathrm{CaO}$ & 89,97 & 2,86 \\
$\mathrm{MgO}$ & 5,85 & 2,81 \\
$\mathrm{SrO}$ & 2,31 & 0,08 \\
$\mathrm{SiO} 2$ & 1,41 & 0,47 \\
$\mathrm{Fe} 2 \mathrm{O} 3$ & 0,277 & 0,097 \\
$\mathrm{TiO} 2$ & 0,079 & 0,015 \\
$\mathrm{Cr} 2 \mathrm{O} 3$ & 0,032 & 0,012 \\
$\mathrm{Nb} 2 \mathrm{O} 5$ & 0,0238 & 0,0068 \\
$\mathrm{MoO} 3$ & 0,0159 & 0,0064 \\
$\mathrm{SnO} 2$ & 0,0083 & 0,0014 \\
$\mathrm{In} 2 \mathrm{O} 3$ & 0,0081 & 0,0011 \\
$\mathrm{Sb} 2 \mathrm{O} 3$ & 0,0079 & 0,0014 \\
$\mathrm{RuO} 4$ & 0,0074 & 0,0029 \\
\hline
\end{tabular}

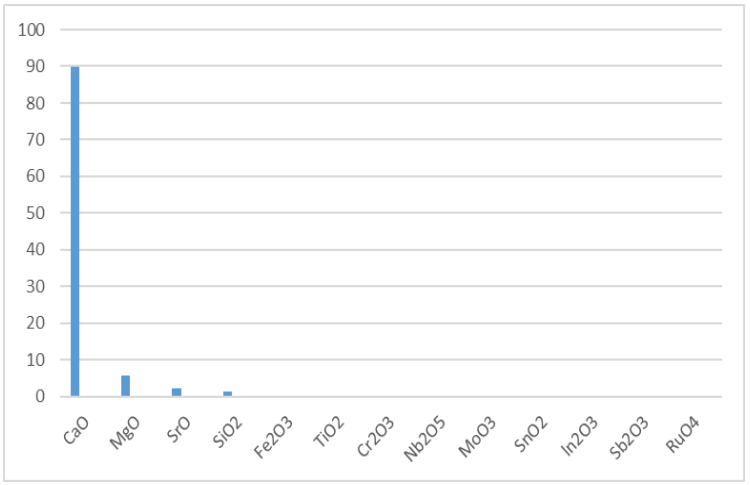

Gambar 3. Persentasi Senyawa dalam Sampel Pasir Putih.

\section{Hasil Uji XRD}

Silika yang di peroleh dari ekstraksi pasir putih dengan metode Alkali Fusion selanjutnya di analisis menggunakan XRD yang di uji di Laboratorium FMIPA UNM Makasar. 


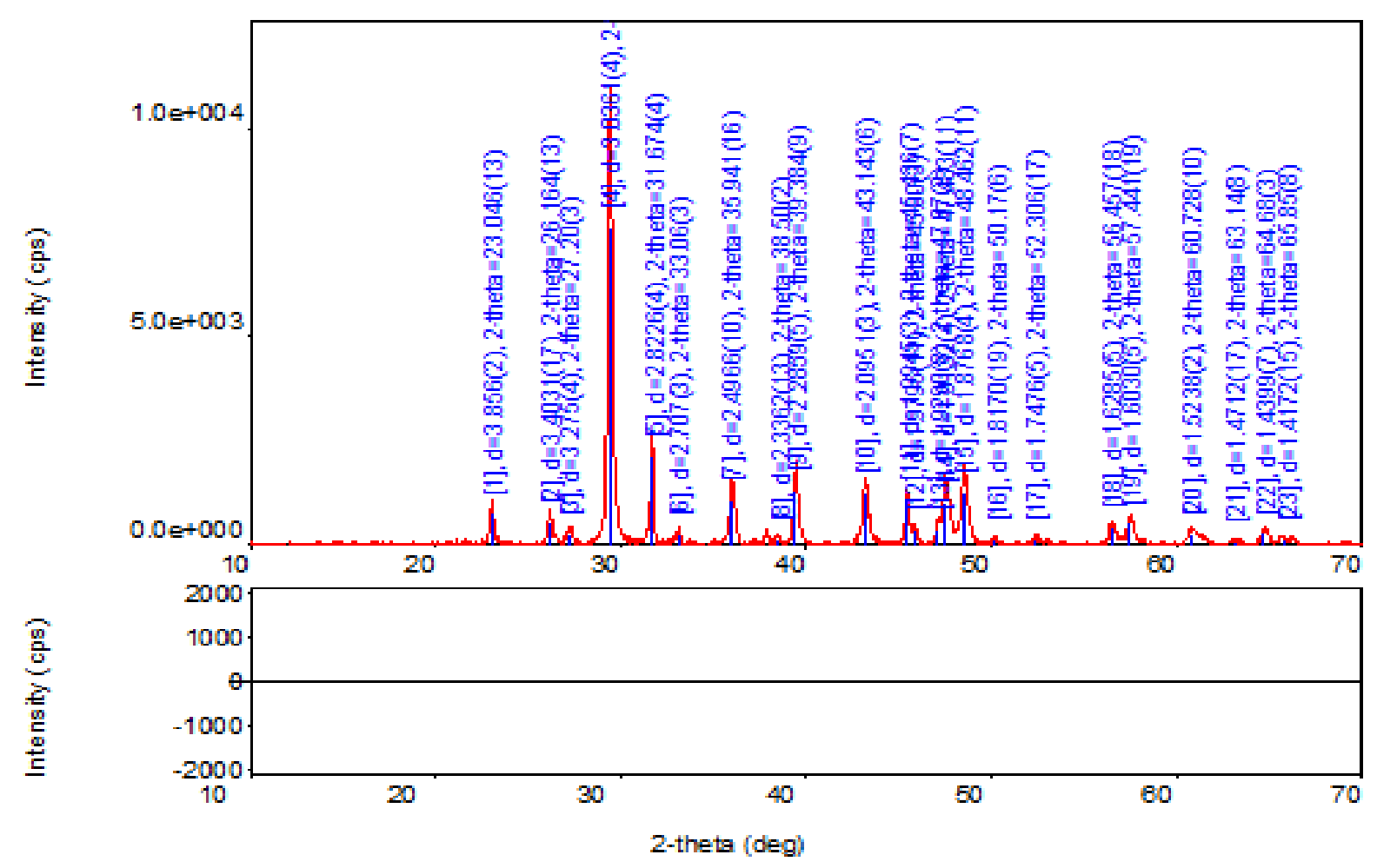

Gambar 4. Spektrum sampel pada XRD

Karakteristik dari silika yang terdapat pada serbuk endapan silika hasil Ekstraksi dimana sumbu $X$ (pada Sudut 2-theta) dan sumbu Y ( Intensitas ) dimana uji Difraksi Sinar$X$ di lakukan pada sudut (10-700). Hasil Karakterisasi pasir putih dengan difraksi sinar$\mathrm{X}$ menunjukan pola difraksi pasir putih sesuai dengan data base yang ada pada ICSD untuk silika $\left(\mathrm{SiO}_{2}\right)$ Melalui analisis dari 23 puncak (Tabel peak XRD) pola difraksi pada sudut (10-

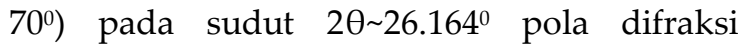
menunjukan intensitas yang sedang. Dari hasil tersebut maka dapat di ajukan bahwa sampel pasir putih mengandung $\mathrm{SiO}_{2}$ (Quartz) dimana data ini juga di dukung dengan pengujian melalui identifikasi menggunakan XRF dimana komposisi silika $\left(\mathrm{SiO}_{2}\right)$ sebanyak $1,41 \%$,melalui data tersebut silika $\left(\mathrm{SiO}_{2}\right)$ merupakan salah satu penyusun komponen utama pada pasir putih dari desa marinsow kabupaten minahasa utara (Gambar 4).

Pada sudut 20 29.394 pola difraksi menunjukan intensitas yang sangat tinggi dan dari hasil tersebut dapat di ajukan bahwa sampel pasir putih mengandung $\mathrm{CaO}$ (Kalsit). Data ini juga di dukung dengan adanya data pada pengujian menggunakan XRF dimana $\mathrm{CaO}$ merupakan Komponen utama yang paling besar penyusun pasir putih di desa marinsow yakni sebanyak 89,97\%. Komponen-komponen lain yang yang terdapat pada pasir putih dari desa marinsow kabupaten minahasa utara antara lain $\mathrm{MgO}$ sebanyak 5,85\%,SrO sebanyak $2,31 \%, \mathrm{Fe}_{2} \mathrm{O}_{3}$ sebanyak $0,277 \%, \mathrm{TiO}_{2}$ sebanyak $0,079 \%, \mathrm{Cr}_{2} \mathrm{O}_{3}$ yakni $0,032 \%, \mathrm{Nb}_{2} \mathrm{O}_{5}$ yakni $0,0238 \%, \mathrm{MoO}_{3}$ sebanyak 0,0159\%, $\mathrm{SnO}_{2}$ sebanyak 0,0082 \%, $\mathrm{Sb}_{2} \mathrm{O}_{3}$ 0,0079 \% dan $\mathrm{RuO}_{4}$ sebanyak $0,0074 \%$.

\section{Kesimpulan}

Hasil pengujian XRF dan XRD menunjukkan bahwa pasir putih yang berasal dari desa Marinsow Minahasa Utara mempunyai komposisi kimia $\mathrm{CaO}$ (kalsit) dengan tingkat kemurnian yang tinggi yakni $89,97 \%$ dan Silicon Dioksida $\left(\mathrm{SiO}_{2}\right)$ berupa Quartz dalam jumlah yakni 1,41\%. Dan pasir putih dari desa marinsow memiliki komponenkomponen kimia seperti MgO sebanyak 5,85 $\%$,SrO sebanyak 2,31 \%, $\mathrm{Fe}_{2} \mathrm{O}_{3}$ sebanyak $0,277 \%$, $\mathrm{TiO}_{2}$ sebanyak $0,079 \%, \mathrm{Cr}_{2} \mathrm{O}_{3}$ yakni $0,032 \%$, $\mathrm{Nb}_{2} \mathrm{O}_{5}$ yakni $0,0238 \%, \mathrm{MoO}_{3}$ sebanyak $0,0159 \%$, $\mathrm{SnO}_{2}$ sebanyak $0,0082 \%, \mathrm{Sb}_{2} \mathrm{O}_{3} \quad 0,0079 \%$ dan $\mathrm{RuO}_{4}$ sebanyak $0,0074 \%$. 


\section{Daftar Pustaka}

1. Hadi, S.; Munasir, M.; Triwikantoro, T. Sintesis Silika Berbasis Pasir Alam Bancar menggunakan Metode Kopresipitasi. Jurnal Fisika dan Aplikasinya 2011, 7, 110202-1.

2. Siswanto, M. Perekayasaan Nanosilika Berbahan Baku Silika Lokal Sebagai Filler Kompon Karet Rubber Air Bag Peluncur Kapal dari Galangan.; Insinas; 2012; pp. 5659.

3. Barsoum, M. Fundamentals of ceramics; CRC press, 2019;

4. Masduqi, A. Penyisihan Fosfat Dengan Proses Kristalisasi dalam Reaktor Terfluidisasi Menggunakan Media Pasir Silika. Jurnal Purifikasi 2003, 4, 151-156.

5. Hurlbut, C.S.; Klein, C. Manual of mineralogy (after James D. Dana); Wiley, 1977;

6. Purbarani, M.E.; Pratapa, S. Analisis Rietvield Data Difraksi Kristobalit Hasil Sintesis dengan Metode Kopresipitasi. Jurnal Sains dan Seni ITS 2014, 3, B123-B125.

7. McColm, I.J.; Phil, D. Ceramic science for materials technologists; Hill, 1983;

8. Liu, X.; Colman, S.M.; Brown, E.T.; Minor, E.C.; Li, H. Estimation of carbonate, total organic carbon, and biogenic silica content by FTIR and XRF techniques in lacustrine sediments. Journal of Paleolimnology 2013, 50, 387-398.

9. Brown, E.T. Estimation of biogenic silica concentrations using scanning XRF: insights from studies of Lake Malawi sediments. In Micro-XRF Studies of Sediment Cores; Springer, 2015; pp. 267-277.

10. Fahmi, H.; Nurfalah, A.L. Analisa daya serap silika gel berbahan dasar abu sekam padi. Jurnal Ipteks Terapan 2016, 10, 176-182.

11. Ermrich, M.; Opper, D. XRD for the analyst. Getting acquainted with the principles. Second. Panalytical 2013.

12. Nayak, P.S.; Singh, B.K. Instrumental characterization of clay by XRF, XRD and FTIR. Bulletin of Materials Science 2007, 30, 235-238.

13. Treacy, M.M.; Higgins, J.B. Collection of simulated XRD powder patterns for zeolites fifth (5th) revised edition; Elsevier, 2007;

14. Setiabudi, A.; Rifan, H.; Ahmad, M. Karakterisasi Material; Bandung: UPI PRESS,
2012;

15. Suslick, K.S. Kirk-Othmer encyclopedia of chemical technology. J. Wiley \& Sons: New York 1998, 26, 517.

16. Wianto, T.; Sari, N.; Darminto, D.; Pratapa, S. Sintesis dan karakterisasi nanosilika sebagai upaya pemanfaatan potensi sumberdaya Banjarbaru. Jurnal Fisika Flux: Jurnal Ilmiah Fisika FMIPA Universitas Lambung Mangkurat 2010, 7, 53-65.

17. Meirawati, D.; Wardhani, S.; Tjahjanto, R.T. Studi Pengaruh Konsentrasi $\mathrm{HCl}$ Dan Waktu Aging (Pematangan Gel) Terhadap Sintesis Silika Xerogel Berbahan Dasar Pasir Kuarsa Bangka. Jurnal Ilmu Kimia Universitas Brawijaya 2013, 2, pp-524.

18. Ramadhan, N.I.; Munasir, M. Sintesis dan Karakterisasi Serbuk SiO2 dengan Variasi $\mathrm{pH}$ dan Molaritas Berbahan Dasar Pasir Bancar, Tuban. Jurnal Sains dan Seni ITS 2014, 3, B15-B17.

19. Susanti, S.; Widiarti, N.; Prasetya, A.T. Sintesis Silika Gel Teraktivasi dari Pasir Kuarsa untuk Menurunkan Kadar ION Cu2+ dalam Air. Jurnal Mipa 2017, 40, 3942.

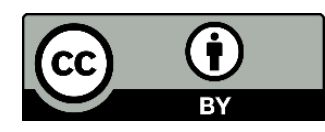

(C) 2020 by the authors. Licensee Fullerene Journal Of Chem. This article is an open access article distributed under the terms and conditions of the Creative Commons Attribution (CC BY) license

(http://creativecommons.org/licenses/by/4.0/) 